\title{
Chlorophyll a might structure a community of potentially pathogenic culturable Vibrionaceae. Insights from a one-year study of water and mussels surveyed on the French Atlantic coast
}

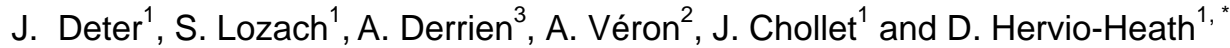

\footnotetext{
${ }^{1}$ Ifremer, centre de Brest, Département Environnement, Microbiologie et Phycotoxines (EMP), Laboratoire de Microbiologie, ZI de la pointe du diable, B.P. 70, 29280 Plouzané, France.

${ }^{2}$ Ifremer, centre de Nantes, EMP/Laboratoire National de Référence Microbiologie des Coquillages, BP 21105, 44311 Nantes Cedex 3, France.

${ }^{3}$ Ifremer, LERPC, centre de La Rochelle, place Gaby Coll, BP 7, 17137 L'Houmeau, France.

*: Corresponding author: D. Hervio-Heath, Tel. (+33) 2982243 49; Fax (+33) 2982245 94, email address : Dominique.Hervio.Heath@ifremer.fr
}

\begin{abstract}
:
The present study focused on the isolation of culturable bacteria from mussels and sea water to identify Vibrionaceae potentially pathogenic for humans. Three sites located on the French Atlantic coast were monitored monthly (twice each month during summer) for 1 year. Environmental parameters were surveyed (water temperature, salinity, turbidity, chlorophyll a) and bacteria were detected by culture and identified by API 20E ${ }^{\circledR}$ systems (BioMérieux) and PCR. A total of seven species were detected (Grimontia hollisae, Photobacterium damselae, Vibrio alginolyticus, V. cholerae, $V$. fluvialis, $V$. vulnificus and $V$. parahaemolyticus) and species diversity was higher at the end of summer. Surprisingly, V. cholerae non-O1/non-O139 was detected in spring. No site effect was detected. Using Sørensen similarity indices and statistical analyses, we showed that chlorophyll a had a significant influence on the bacterial community detected in mussels and assemblages were more similar to one another when chlorophyll a values were above $20 \mu \mathrm{gl}^{-1}$. No significant effect of any parameter was found on the community detected in water samples. Such surveys are essential for the understanding of sanitary crises and detection of emerging pathogens.
\end{abstract}


2 Many micro-organisms (microalgae, bacteria and heterotrophic protists) are naturally present

3 in sea water. They are used as food resources (Langdon and Newell, 1990) by filter-feeding

4 animals and may be accumulated in their tissues. Some of these bacteria, especially the

5 Vibrionaceae, may be pathogenic and cause human diseases (gastro-enteritis, wound tissue

6 infections or septicaemia) after seafood consumption or contact between a wound and water.

7 Vibrio cholerae, V. parahaemolyticus and V. vulnificus are distributed worldwide and 8 responsible for most food-borne infections caused by bacteria. Toxigenic strains of $V$. 9 cholerae are the aetiological agents of cholera, causing more than 230000 human cases, including over 6000 deaths, in 52 countries in 2006 (WHO, 2008). V. parahaemolyticus is recognized as the leading cause of human gastroenteritis associated with seafood consumption

12 in the United States of America (USA) and Japan, but the incidence is low in Europe (Su and Liu, 2007). Primary septicaemia due to $V$. vulnificus is the most deadly food-borne disease in the USA accounting for $95 \%$ of all seafood-related deaths, with a mortality rate of approximately $50 \%$ (Oliver, 2006). Other vibrios responsible for occasional severe infections are also found in the marine environment: V. alginolyticus (Rubin and Tilton, 1975), Grimontia hollisae (formerly V. hollisae) (Hinestrosa et al., 2007), and Photobacterium damselae damselae (formerly Listonella or V. damselae) (Osorio et al., 2005). Pathogenesis by these bacteria is often due to their ability to secrete extracellular virulence factors, whose nature may be more or less well known (Nishibuchi and Kaper, 1995; Oliver and Kaper, 21 2007).

Vibrionaceae bacteria are particularly important for the seafood economy because pre-market depuration processes (before mollusc sale) generally fail to eliminate these microorganisms from shellfish, although they do eliminate conventional bacterial indicators (Escherichia coli) which are less strongly bound to mollusc tissues ( $\mathrm{Su}$ and Liu, 2007). Consequently, the 
1 improvement of our understanding of the ecological processes influencing Vibrionaceae

2 populations is particularly relevant for the management of preventive actions. Such ecological

3 studies are becoming increasingly numerous, especially in USA where the distribution of

4 some coastal Vibrio populations is linked to environmental factors, including water

5 temperature and salinity (Kaneko and Colwell, 1978; Mercedes et al., 2000; Duan and Su,

6 2005; Oliver and Kaper, 2007; Blackwell and Oliver, 2008; Johnson et al. 2009). However,

7 studies focusing on a global microbial community and its links with the environment remain

8 scarce (Licciano et al., 2007), even though methods for evaluating structure in bacterial

9 community composition or the influence of environmental factors already exist (Clarke et al., 10 2008).

11 In France (the third largest mussel-producing country in Europe (IFREMER, 2006)), only a 12 few environmental studies have focused on potentially pathogenic vibrios (Hervio-Heath et al., 2002; Robert-Pillot et al., 2004). The presence of V. alginolyticus, V. parahaemolyticus, $V$. vulnificus and $V$. cholerae non-O1/non-O139 has been observed in mussels (Mytillus edulis) and water at different sites (Hervio-Heath et al., 2002; Robert-Pillot et al., 2004). In the Pertuis Breton (Atlantic coast), a recent one-year study investigated the ecology of $V$. parahaemolyticus (Deter et al., accepted). The results showed that water temperature and turbidity had an effect on the presence of total $V$. parahaemolyticus in water, but that chlorophyll $a$ was the most important factor influencing the presence of the bacteria in mussels. In the present study, we monitored sea water and mussels (Mytillus edulis) at the same three sampling sites (Figure 1) for one year (one sampling per month, two per month from May to August). The purposes of the study were, first, to identify (presence/absence of species) the community of culturable potentially pathogenic Vibrionaceae and, then, to investigate the influence of environmental factors (water temperature, salinity, turbidity and 
1 species and the presence of total $V$. parahaemolyticus (results from Deter et al. accepted) on

2 the structure of this entire community.

RESULTS AND DISCUSSION

\section{Description of the data}

5 All environmental parameters showed spatio-temporal variation during the study period

6 (April 08-March 09): mean water temperature varied from 6.7 to $22.0{ }^{\circ} \mathrm{C}$; salinity from 26.0

7 to 35.6 (no unit), with maximal values during summer; turbidity from 1.4 to $40.3 \mathrm{FNU}$

8 (formazin nephtelometric units), with maxima in April and November-December; chlorophyll

$9 \quad a$ from 0.6 to $22.0 \mu \mathrm{g} / \mathrm{L}$, with maxima in June; and the number of culturable bacteria from 27

to 6400 bacteria / g mussel tissue (maxima in January) and from 0 to 24 bacteria / $\mathrm{ml}$ sea

11 water (maxima during summer). Total culturable Vibrionaceae presented higher densities in

12 mussels than in the surrounding water throughout the year (maximal MPN [most probable number of bacteria]) in mussels 6400 / g > 24 / $\mathrm{ml}$ sea water, Fig. 2). All of these parameters were adequately (log or square root) transformed to fit a normal distribution. Both MPN variables were highly correlated ( $\mathrm{r}=0.400, P=0.005)$. A highly significant linear relationship was found between MPN of bacteria estimated in sea water and MPN of bacteria in mussels (Figure 2, linear regression, $R^{2}=0.14, F=8.75, P=0.005$ ). This meant that the concentration in the seawater could explain that in mussels and thus confirmed the ability of mussels to accumulate bacteria from surrounding environment, as already shown by Cavallo et al. (2009).

\section{Structure of the Vibrionaceae community and influence of the environment}

Bacterial isolates obtained from this study yielded very good to excellent identification using the API 20E® system, and Vibrio species were confirmed with conventional or Real-Time PCR (RT-PCR). Seven species were detected (Table 1). The presence of G. holissae is noteworthy as infection has never been reported on the European Atlantic coast except for one 
1 human case 13 years ago in France (GrasRouzet et al., 1996). All of the other species detected

2 in this study had already been reported by Hervio-Heath et al. (2002) at Filière W after three

3 sampling campaigns in summer 1999. As reported in other studies on samples from Europe

4 and America, the most frequently isolated bacteria were $V$. alginolyticus (39 positive mussel

5 samples out of 48 and 35/48 in water) and V. parahaemolyticus (17/48 in mussels and 16/48

6 in water) (Croci et al., 2001; Hervio-Heath et al., 2002; Blackwell and Oliver, 2008;

7 Martinez-Urtaza et al., 2008). The present one-year survey highlighted a higher diversity of

8 bacterial species at the end of the summer (August-September, 4.5 species detected in mean)

9 after maximal values of water temperature and salinity, two factors frequently reported as having an influence on these species (see Introduction). Surprisingly, $V$. cholerae non-

O1/non-O139 was not detected during the summer but in spring (May in mussels at Filière W and February in sea water at L'Eperon). The detection of $V$. cholerae only in spring could be related to a lower competition of bacterial species on culture plates at this time of the year. The toxigenic form of this bacterium was reported in 36 imported cases of cholera in European Union in 2005 (ECDC, 2008). Contrary to toxigenic strains, which are rarely isolated, non toxigenic strains are normal inhabitants of aquatic ecosystems (Oliver and Kaper, 2007). The species had already been detected at the Filière W site ten years ago by Hervio-Heath et al. (2002). Knowing that V. cholerae non-O1/non-O139 may be associated with cases of gastro-enteritis and a small number of oyster-vectored deaths, notably in USA (Rippey, 1994), a more regular monitoring of this site should be considered.

\section{Influence of total $V$. parahaemolyticus and of the environmental parameters on the}

\section{Vibrionaceae community}

The matrix of Vibrionaceae species detection (presence/absence per date at each site for mussels or sea water) was used to perform a Principal Component Analysis (PCA). All of the species were more or less correlated in their presence/absence (no antagonism between 
1 species, see Fig.3 for water; similar results were obtained for mussels, data not shown). This

2 suggested that similar parameters might influence each species and structure the entire

3 community.

4 Analysis of similarities (ANOSIM), an approximate analogue of analysis of variance, was

5 conducted to test the null hypothesis that there were no assemblage differences between

6 groups of samples specified by a single qualitative factor (here sampling site or the

7 presence/absence of total $V$. parahaemolyticus, as described in Deter et al. (accepted), with a

8 RT-PCR detection after enrichment). The analyses were performed with Primer 6.1.11

9 software (Primer-E Ltd), according to Clarke and Gorley (2006), Clarke and Warwick (2001)

10 and Clarke et al. (2008).

11 ANOSIM performed on the water similarity matrix did not show any significant effect of site

$12(P=0.93)$ or of the presence of total $V$. parahaemolyticus $(P=0.20)$. The BEST BIO-ENV

13 procedure was then used to find the "best" match between the multivariate among-sample

14 patterns of the assemblages (in water or mussels) and that from quantitative variables (water

15 temperature, salinity, turbidity, chlorophyll $a$, MPN in water or in mussel) associated with

16 those samples. This procedure was used to search (using all combinations of variables) for

17 high rank correlations (called $\rho$ ) between the similarity matrix (species assemblage) and

18 resemblance matrix (Euclidian distance), generated with environmental data. $P$-values were

19 obtained with permutation tests (10000 permutations). In water samples, no parameters had a

20 significant influence on the structure of the community $(P>0.17)$. Consequently, other

21 parameters that were not taken into account in the study (such as zooplankton or other

22 bacteria, for example) should be considered as potentially more important.

23 In mussels, there was no significant difference between the groups of communities when sites

24 were considered (ANOSIM, $P=0.42$ ), most probably because of the small spatial scale

25 considered in this study (distance between sites ranged from 5 to $10 \mathrm{~km}$ ). Presence of total $V$. 
1 parahaemolyticus in mussels (Deter et al., accepted) had a significant influence on the

2 similarities calculated between the assemblages observed in mussels (ANOSIM, $P=0.03$ ). $\rho$

3 was optimised (0.325) with a model containing chlorophyll $a$ and turbidity but the best one-

4 variable solution produced a result that was almost as good with chlorophyll $a$ alone

$5(\rho=0.322 ; P=0.007)$ and which, on grounds of parsimony, might be preferable. Dissimilar

6 samples were observed when chlorophyll $a$ values were inferior to $18 \mu \mathrm{g} / \mathrm{L}$. Samples

7 presenting more similar assemblages were found when chlorophyll $a$ presented values above

$820 \mu \mathrm{g} / \mathrm{L}$ (Fig. 4). As an explanation, we suggest the influence of a link between chlorophyll $a$

9 - phytoplankton - zooplankton but unfortunately, were not able to monitor zooplankton

10 during this study. $V$. parahaemolyticus populations are known to be influenced by a factor

11 related to plankton (planktonic species, plankton detritus, or other particulate matter trapped

12 during plankton hauls) because of the attachment and/or a chitinoclastic activity (Kaneko et

13 al., 1973). In Deter et al. (accepted), the authors already linked the presence of total $V$.

14 parahaemolyticus to chlorophyll $a$. This would not be due to the bloom of any of the

15 phytoplanktonic species reported in Deter et al (accepted) but more to an overall effect or to

16 the influence of zooplankton in relation with phytoplankton linked in turn to chlorophyll $a$. In

17 the present study, chlorophyll $a$ was also the parameter that most influenced the Vibrionaceae

18 community found in mussels, indicating that attachment to plankton and chitinoclastic activity

19 are characteristics shared by all Vibrionaceae. This would confirm the increasing role in

20 ecology given to attachment and microbial biofilms for a majority of bacteria (Yildiz and

21 Visick, 2008; Monds and O'Toole, 2009).

22 The present study showed a high diversity of potentially pathogenic Vibrionaceae on the

23 French Atlantic coast. It is important to pursue such studies by including abundance values.

24 Ecological studies on bacterial communities are still rare in Europe, but they could be very

25 valuable in the event of environmental disorders (oyster summer mortalities (IFREMER, 
1 2008)) or sporadic human cases (death after a $V$. vulnificus infection (DDASS Hérault,

2 2008)). Thus, such surveys would be important for the detection of emerging pathogens

3 and/or to have knowledge of initial states in case of sanitary crises.

4

5

\section{REFERENCES}

Blackwell, K.D., and Oliver, J.D. (2008) The ecology of Vibrio vulnificus, Vibrio cholerae and Vibrio parahaemolyticus in North Carolina estuaries. J Microbiol 46: 1-8.

Cavallo, R.A., Acquaviva, M.I., and Stabili, L. (2009) Culturable heterotrophic bacteria in seawater and Mytillus galloprovincialis from a Mediterranean area (Northern Ionian sea Italy). Environ Monit Assess 14: 465-475.

Chun, J., Huq, A., and Colwell, R.R. (1999) Analysis of 16S-23S r RNA Intergenic Spacer Regions of Vibrio cholerae and Vibrio mimicus. Appl Environ Microbiol 65: 2202-2208. Clarke, K.R., and Warwick, R.M. (2001) Change in marine communities: an approach to statistical analysis and interpretation, 2nd edition. In PRIMER-E. Plymouth.

Clarke, K.R., and Gorley, R.N. (2006) PRIMER v6: User Manual/Tutorial. In PRIMER-E. Plymouth.

Clarke, K.R., Somerfield, P.J., and Gorley, R.N. (2008) Testing of null hypotheses in exploratory community analyses: similarity profiles and biota-environment linkage. J ExpMar Biol Ecol 366: 56-69.

Croci, L., Serratore, P., Cozzi, L., Stacchini, A., Milandri, S., Suffredini, E., and Toti, L. (2001) Detection of Vibrionaceae in mussels and in their seawater growing area. Lett Appl Microbiol 32: 57-61.

Deter, J., Lozach, S., Derrien, A., Véron, A., Chollet, J., and Hervio-Heath D. (accepted). Ecology of pathogenic and non-pathogenic Vibrio parahaemolyticus on the French Atlantic coast. Effect of temperature, salinity, turbidity and chlorophyll a. Env Microbiol 
1 DDASS Hérault (2008). Infection à Vibrio vulnificus avec décès suite à une séance de pêche

2 dans l'étang de Vic (Hérault)

3 Duan, J., and Su, Y. (2005) Occurrence of Vibrio parahaemolyticus in two Oregon oyster-

4 growing bays. J Food Sci 70: M58-M63.

5 ECDC, The European Centre for Disease Prevention and Control (2008) Questionnaire for the

6 first European communicable disease epidemiological. In: European commission- Health and

7 consumers directorate general DG SANCO / Eurostat.

8 GrasRouzet, S., Donnio, P.Y., Juguet, F., Plessis, P., Minet, J., and Avril, J.L. (1996) First

9 European case of gastroenteritis and bacteremia due to Vibrio hollisae. Eur J Clin Microbiol 15: 864-866.

Hervio-Heath, D., Colwell, R.R., Derrien, A., Robert-Pillot, A., Fournier, J.-M., and Pommepuy, M. (2002) Occurence of pathogenic vibrios in coastal areas of France. J Appl Microbiol 92: 1123-1135.

Hinestrosa, F., Madeira, R.G., and Bourbeau, P.P. (2007) Severe gastroenteritis and hypovolemic shock caused by Grimontia (Vibrio) hollisae infection. J Clin Microbiol 45: 3462-3463.

IFREMER (2006). Aquaculture - Filière mollusques [www document]. URL http://wwz.ifremer.fr/aquaculture/filieres/filiere_mollusques/decouverte_mollusques IFREMER (2008). Oyster (Crassostrea gigas) mortality events during summer 2008 in France [www document]. URL http://www.ifremer.fr/crlmollusc/page_labo/News.htm Johnson C.N., Flowers, A.R., Young, VC, Gonzalez-Escalona, N., DePaola, A., Noriea, N.F., and Grimes, D.J. (2009) Genetic relatedness among tdh+ and trh+ Vibrio parahaemolyticus 
1 Kaneko, T., and Colwell, R.R. (1973) Ecology of Vibrio parahaemolyticus in Chesapeake

$2 \quad$ Bay. J Bacteriol 113: 24-32.

3 Kaneko, T., and Colwell, R.R. (1978) Annual cycle of Vibrio parahaemolyticus in

4 Chesapeake Bay. Microbiol Ecol 4: 135-155.

5 Langdon, C.J., and Newell, R.I.E. (1990) Utilization of detritus and bacteria as food sources

6 by two bivalve suspension-feeders the oyster Crassostrea virginica and the mussel Geukensia

7 demissa. Mar Ecol: Progress Series 58: 299-310.

8 Lee, J.Y., Eun, J.b., and Choi, S.H. (1997) Improving detection of Vibrio vulnificus in

9 Octopus variabilis by PCR. J Food Sci 62: 179-182.

Licciano, M., Terlizzia, A., Giangrandea, A., Cavallob, R.A., and Stabilia, L. (2007) Filterfeeder macroinvertebrates as key players in culturable bacteria biodiversity control: a case of study with Sabella spallanzanii (Polychaeta: Sabellidae). Mar Environ Res 64: 504-513. Martinez-Urtaza, J., Lozano-Leon, A., Varela-Pet, J., Trinanes, J., Pazos, Y., and GarciaMartin, O. (2008) Environmental determinants of the occurence and distribution of Vibrio parahaemolyticus in the rias of Galicia, Spain. Appl Environ Microbiol 74: 265-274.

Mercedes, P., Rodo, X., Ellner, S.P., Colwell, R., and Bouma, M.J. (2000) Cholera Dynamics and El Nino-Southern Oscillation. Science 289: 1766-1769.

Monds, R.D., and O'Toole, G.A. (2009) The developmental model of microbial biofilms: ten years of a paradigm up for review. Trends Microbiol 17: 73-87.

Nishibuchi, M., and Kaper, J.B. (1995) Thermosatble direct hemolysin gene of Vibrio parahaemolyticus: a virulence gene acquired by a marine bacterium. Infect Immun 63: 20932099.

Nhung, P.H., Ohkusua, K., Miyasakab, J., Suna, X. S., and Ezakia, T. (2007) Rapid and specific identification of 5 human pathogenic Vibrio species by multiplex polymerase chain reaction targeted to dnaJ gene. Microbiol Infect Dis 59: 271-275. 
1 Oliver, J.D. (2006) Vibrio vulnificus. In Biology of Vibrios. Thompson, F.L., Austin, B., and

2 Swing, J. (eds). Washington, D.C., USA: American Society of Microbiology Press.

3 Oliver, J.D., and Kaper, J.B. (2007) Vibrio species. In Food microbiology: fundamentals and

4 frontiers. Doyle, M.P., and Beuchat, L.R. (eds). Washington, D. C., USA: American Society

5 of Microbiology.

6 Osorio, C.R., Collins, M.D., Romalde, J.L., and Toranzo, A.E. (2005) Variation in 16S-23S

7 rRNA intergenic spacer regions in Photobacterium damselae: a mosaic-like structure. Appl

$8 \quad$ Environ Microbiol 71: 636-645.

9 Rippey, S.R. (1994) Infectious diseases associated with molluscan shellfish consumption.

$10 \quad$ Clin Microbiol Rev 4: 419-425.

11 Robert-Pillot, A., Guénolé, A., Lesne, J., Delesmont, R., Fournier, J.-M., and Quilici, M.-L.

12 (2004) Occurence of the $t d h$ and trh genes in Vibrio parahaemolyticus isolates from waters

13 and raw shellefish collected in two French coastal areas and from seafood imported into

14 France. Intern J Food Microbiol 91: 319-325.

15 Rubin, S.J., and Tilton, R.C. (1975) Isolation of Vibrio alginolyticus from Wound Infections.

16 J Clin Microbiol 2: 556-558.

17 Su, Y.-C., and Liu, C. (2007) Vibrio parahaemolyticus: A concern of seafood safety. Food

18 Microbiol 24: 549-558.

19 WHO, World Health Organization (2008) Cholera. Fact sheet N¹07.

20 Yildiz, F.H., and Visick, K.L. (2008) Vibrio biofilms: so much the same yet so different.

21 Trends Microbiol 17: 109-118. 
2 Table 1. Vibrionaceae species detected during the one-year study with the number of

3 occurrences (total number $=16$ dates for each species) per site and origin of sample.

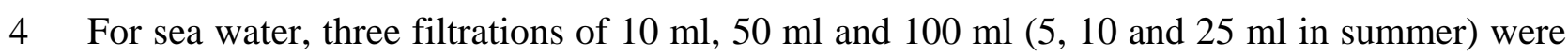
5 realized for each site. Filters (nitrocellulose $0.22 \mu \mathrm{m} \varnothing 47 \mathrm{~mm}$, Millipore) were deposited 6 onto three different culture media: Difco $^{\mathrm{TM}}$ Marine Agar 2216 (Becton Dickinson and 7 Company), Difco ${ }^{\mathrm{TM}}$ Thiosulfate Citrate Bile Salts Sucrose agar (Becton Dickinson and 8 Company), and CHROMagar ${ }^{\mathrm{TM}}$ Vibrio (CHROMagar Paris France). One filter was deposited 9 per plate (three plates / culture medium / site). Concerning the mussels, the 1:2 dilutions of mussel tissue (see Fig. 2) were made and spread onto the three media (1:2, 1:20 and 1/200 dilutions). All plates were incubated $24 \mathrm{~h}$ at $37{ }^{\circ} \mathrm{C}$ (temperature and media selecting for

12 Vibrionaceae bacteria). Presumptive Vibrionaceae were isolated (one colony of each morphotype per source/culture medium/site/date) and identified as described hereafter.

14 Biochemical analyses were performed from cultures of isolated colonies grown onto Bacto ${ }^{\mathrm{TM}}$ Heart Infusion medium with 2\% $\mathrm{NaCl}$ (Becton Dickinson and Company) and incubated for 20-24 h at $37{ }^{\circ} \mathrm{C}$. Biochemical tests (oxydase test, API 20E® system: BioMérieux, France) were performed following classical procedures. Real time-PCR on MX3000P $\mathrm{P}^{\mathrm{TM}}$ (Stratagene) were performed to detect $V$. parahaemolyticus (toxR gene, patent pending). Conventional PCR PTC-200 (Mj Research) was used to confirm the identification of Vibrio sp bacteria: $V$. alginolyticus with primers VM-F and V.al2-MmR for the dnaJ gene (Nhung et al, 2007), V. 21 vulnificus with VV-1 and VV-2R for the $v v h$ hemolysin gene (Lee et al., 1997), and V. 22 cholerae with prVC-F and prVCM-R for the 16S-23S rRNA Intergenic Spacer Regions (Chun 23 et al., 1999) as already described by Hervio-Heath et al. (2002). Confirmed V. cholerae strains were sent to the Centre National de Référence des Vibrions et du Choléra (CNRVC, 
1 Institut Pasteur, Paris France) to be tested with O1 and O139 antisera and for the presence of

2 the $c t x$ gene related to toxigenic strains.

3 DNA used for these molecular identifications were extracted from a $10 \mu$ l handle of isolated

4 strain following Deter et al. (accepted). The DNA extracts were conserved at $-20^{\circ} \mathrm{C}$ until PCR 5 was performed.

6

\begin{tabular}{lcccccc}
\hline \multicolumn{1}{c}{ Species } & Filière W & $\begin{array}{c}\text { Mussels } \\
\text { La Carrelère }\end{array}$ & L'Eperon & Filiere W & La Carrelère & L'Eperon \\
\hline Grimontia hollisae & 2 & 3 & 0 & 2 & 1 & 0 \\
$\begin{array}{l}\text { Photobacterium damselae } \\
\text { Vibrio alginolyticus }\end{array}$ & 2 & 2 & 3 & 2 & 3 & 4 \\
Vibrio cholerae & 13 & 12 & 14 & 11 & 12 & 12 \\
non-O1/non-O139 & 1 & 0 & 0 & 0 & 0 & 1 \\
Vibrio fluvialis & 2 & 1 & 4 & 5 & 6 & 4 \\
Vibrio parahaemolyticus & 7 & 6 & 4 & 4 & 7 & 5 \\
Vibrio vulnificus & 1 & 4 & 4 & 3 & 6 & 5 \\
\hline
\end{tabular}

7

8

9 
2 Figure 1. Map of the Pertuis Breton showing the locations of the sampling sites. These sites

3 were monitored monthly (twice each month during summer) for one year for water and

4 mussel samples. Environmental parameters (water temperature, salinity, turbidity chlorophyll

5 a) and bacteria were surveyed at the same frequency.

6

7 Figure 2. Variation of the square-root transformed most probable number (MPN) of bacteria estimated in mussel (per g of mussel tissue) as a function of the square-root transformed number estimated in water (per ml of water). Regression equation: $\mathrm{Y}=5.654+0.3369 * \mathrm{X}$. For the MPN method, around $200 \mathrm{~g}$ of mussel tissue per site were blended (3 x 20 sec. at high speed with a sterile Waring blender) and 1:2 diluted with sterile alkaline peptone water $1 \%$ $\mathrm{NaCl}$ (APW, 20 g Bacto $^{\mathrm{TM}}$ peptone Becton Dickinson and Company, $10 \mathrm{~g} \mathrm{NaCl}$ per liter, $\mathrm{pH}$ 8.2). Water samples of $800 \mathrm{ml}$ from each site were filtered (nitrocellulose $0.22 \mu \mathrm{m}$, Millipore). Deposits from filters were re-suspended in $25 \mathrm{ml}$ (40 $\mathrm{ml}$ for l'Eperon and La Carrelère in summer) of sterile artificial sea water (water and Instant Ocean Sea Salt®, Instant Ocean). Re-suspended deposits from sea water and a 1:5 APW dilution of the 1:2 mussel homogenate were used for the MPN with three series of six tubes. Each series corresponded to a $1: 10,1: 100$ and $1: 1000$ dilution (with APW). Tubes were incubated $20 \mathrm{~h}$ at $41{ }^{\circ} \mathrm{C}$ (with a negative control per series at $4{ }^{\circ} \mathrm{C}$ ). The number of total potentially pathogenic Vibrionaceae bacteria culturable at $41{ }^{\circ} \mathrm{C}$ (selection of Vibrionaceaes) was estimated using Mac Grady tables. A link between MPN in mussels and in water was sought by performing a linear regression using Statistica 6.1 (StatSoft, Inc.).

Figure 3. Principal Component Analysis (PCA) based on the presence/absence of the seven Vibrionaceae species in water samples. The purpose was to ordinate the samples and project 
1 them onto a "best-fitting" plane (delimited by two or more principal components = axes)

2 explaining as much of the variation in the data as possible. Species projected with the longest

3 vectors (V. parahaemolyticus) are species that structure the data the most. Variables with

4 vectors projected in the same plane may be considered as positively correlated. The analysis

5 was performed with the Primer 6.1.11 software (Primer-E Ltd) according to Clarke and

6 Gorley (2006) and Clarke and Warwick (2001).

7

8 Figure 4. Two-dimensional representation of the relative dissimilarities in Vibrionaceae

9 species composition in the mussel samples. This graph is the result of a non-metric Multi-

Dimensional Scaling (non-metric MDS using Primer 6.1.11 (Primer-E Ltd)) showing that the

data are clearly structured (stress=0.01). Greater chlorophyll $a(\mu \mathrm{g} / \mathrm{l})$ values are represented on the figure by larger circles. Labels of non superposed circles corresponded to the date of the sampling (three first letters of the month) with a capital letter referring to the site ( $\mathrm{F}=$ Filière W, C=La Carrelère and E=L'Eperon). Labels of the superposed circles are omitted for clarity; they correspond to all the remaining samples (11 samples for Filière W, 15 for l'Eperon and 11 for La Carrelère). For this analysis, the presence/absence matrix was transformed into a similarity matrix using Sørensen indices (Bray-Curtis index calculated on presence/absence data). Samples (in 2-D space) are represented as points in such a way that the relative distances separating all points are in the same rank order as relative dissimilarities of the samples as measured by the resemblance matrix. Points that are close together represent samples that are very similar in community composition (OctF and Jun-1C for example). 